\title{
Concussion symptoms and temporary accommodations using a student-centered return to learn care plan
}

\author{
Erik B. Philipson ${ }^{\mathrm{a}, \mathrm{b}, *}$, Emma Gause $^{\mathrm{a}}$, Kelsey M. Conrick ${ }^{\mathrm{a}, \mathrm{c}}$, Scott Erickson $^{\mathrm{d}}$, Amy Muma ${ }^{\mathrm{a}}$, \\ Zhinan Liu ${ }^{\mathrm{e}}$, Rajiv C. Ayyagari ${ }^{\mathrm{f}}$ and Monica S. Vavilala ${ }^{\mathrm{a}, \mathrm{g}}$ \\ ${ }^{a}$ Harborview Injury Prevention and Research Center, Harborview Medical Center, Seattle, WA, USA \\ ${ }^{\mathrm{b}}$ The Undergraduate Program in Neuroscience, University of Washington, Seattle, WA, USA \\ ${ }^{\mathrm{c}}$ School of Social Work, University of Washington, Seattle, WA, USA \\ ${ }^{\mathrm{d}}$ Urban Indian Health Institute, Seattle, WA, USA \\ ${ }^{\mathrm{e}}$ Department of Biochemistry, University of Washington, Seattle, WA, USA \\ ${ }^{\mathrm{f} J o h n s ~ H o p k i n s ~ B l o o m b e r g ~ S c h o o l ~ o f ~ P u b l i c ~ H e a l t h, ~ J o h n s ~ H o p k i n s ~ U n i v e r s i t y, ~ B a l t i m o r e, ~ M D, ~ U S A ~}$ \\ ${ }^{\mathrm{g}}$ Department of Anesthesiology and Pain Medicine, University of Washington, Seattle, WA, USA
}

Received 8 June 2021

Accepted 18 October 2021

\begin{abstract}
.
BACKGROUND: Many students return to school after concussion with symptoms but without formal support.

OBJECTIVE: To examine concussion symptoms and temporary academic accommodations during school use of a four-week student-centered return to learn (RTL) care plan.

METHODS: Five public high schools used the RTL care plan and contributed student-level data after student report of concussion. Data on concussion symptoms, temporary academic accommodations corresponding to reported symptoms, and accommodations provided during RTL care plan use were examined.

RESULTS: Of 115 students, 55\% used the RTL care plan for three (34\%) or four (21\%) weeks. Compared to students whose symptoms resolve within the first two weeks, students who used the RTL care plan for three or four weeks reported more unique symptoms $(P=0.038)$, higher total severity score $(P=0.005)$, and higher average severity per symptom $(P=0.007)$ at week one. Overall, 1,127 weekly accommodations were provided. While least reported, emotional symptoms received corresponding accommodations most often (127/155 reports: 82\% of occurrences).

CONCLUSIONS: Use of an RTL care plan can facilitate the RTL of students with a concussion and may aid in the identification of students who are in need of longer-term support.
\end{abstract}

Keywords: Concussion, return to learn, traumatic brain injury

\footnotetext{
*Address for correspondence: Erik B. Philipson, Harborview Injury Prevention and Research Center, 325 Ninth Avenue Box 359960, Seattle, WA 98104, USA. Tel.: +1 (206) 744 9430; Fax: +1 (206) 744 9962; E-mail: erikbp@uw.edu.
}

\section{Introduction}

Every year in the United States, there are an estimated 1.1-1.9 million youth concussions (Bryan et al., 2016). Students with concussion experience 
physical, cognitive, sleep, and emotional symptoms that affect academic experiences and performance (Corwin et al., 2014; McCrory et al., 2017; Ransom et al., 2015; Sady et al., 2011). While up to $70 \%$ of youth who experience concussion symptoms have symptom resolution within 28 days, many have prolonged symptoms and there is a lack of consensus as to when students should return to the classroom after concussion (Silverberg \& Iverson, 2013; West \& Marion, 2014; Zemek et al., 2016).

Students who receive no additional support and return to the classroom immediately after concussion as well as students who remain out of classroom for an extended period of time following concussion have longer lasting symptoms than those who are supported by a formal return to learn (RTL) process (Brown et al., 2014; Carson et al., 2014; Grady \& Master, 2017). For this reason, the development and implementation of RTL protocols in schools that facilitate student return to the classroom is important. Yet, school-based accommodations vary in scope, format, and delivery. Currently, there is a wide variation in the proportion of students who receive academic accommodations after concussion; a recent systematic review of 180 studies revealed that $17 \%-73 \%$ of students experienced difficulty with return to school or were provided academic accommodations following concussion (Purcell et al., 2019). They also reported that students were more likely to obtain academic accommodations in schools with a concussion policy if they had a medical return to school letter and had regular medical follow-up after concussion (Purcell et al., 2019).

Research in RTL after concussion has largely been conducted in student athletes, leaving a paucity of understanding regarding generalizability of findings to non-athletes (Castile et al., 2012; Chrisman et al., 2019; Gessel et al., 2007; Marar et al., 2012; Marshall et al., 2015; Meehan et al., 2010; O'Connor et al., 2017; Rosenthal et al., 2014). There is also little known about whether implementing an RTL protocol with individualized temporary school accommodations for students can affect concussion symptom recovery. Using a community-engaged research approach, we recently developed an RTL care plan for all students with concussion that had high overall implementation fidelity $(70.6 \%)$, feasibility, and acceptability in 13 public high schools (Conrick et al., 2020). In this study, we examined concussion symptoms and temporary accommodations during school use of a symptom based studentcentered RTL care plan.

\section{Methods}

\subsection{Schools and students}

Thirteen Seattle public high schools used the RTL care plan for enrolled students who reported a diagnosis of concussion to school staff during fall of the 2018 - 2019 school year. All authorized school administrators of participating schools used local processes and approved the use of the RTL care plan. Students who were diagnosed with concussion by a health care provider and reported it to the school, regardless of whether the concussion took place at school or elsewhere, were eligible to receive the RTL care plan by the school. Feasibility and acceptability of the RTL care plan by 13 public high schools were previously reported (Conrick et al., 2020). Five of these 13 Seattle public high schools detailed information on symptoms and corresponding temporary accommodations. Participation was limited to these five schools because of regulatory requirements. Students or their parents were able to opt out of use of the RTL care plan at any point. Schools sent de-identified student RTL care plans to the research team where they were entered into an into an Research Electronic Data Capture (REDCap) database for analysis (Harris et al., 2009).

\subsection{Return to learn care plan and RTL champion}

Each school identified an RTL champion (nurses, athletic directors, administrators, teachers) who administered the RTL care plan to students who reported a concussion diagnoses to school personnel. The RTL care plan care plan guides the school RTL champion to deliver tailored symptom-based temporary accommodation recommendations. Students receiving the RTL care plan met with the RTL champion at least weekly, as long as symptoms persisted, for up to four weeks. The first visit/week of RTL represents the first encounter that students with concussion had with the school RTL champion. Students whose symptoms persisted beyond four weeks were encouraged to seek medical care and referred for formal school-based accommodation consideration. There were no other triggers that promoted the RTL champion to encourage more immediate physician follow-up. Students stopped receiving the RTL care plan and were returned to the classroom without accommodations when all symptoms resolved.

The symptom evaluation portion of the RTL care plan utilized a Symptom Checklist based upon the 
Sport Concussion Assessment Tool - 5th Edition (SCAT5) which addresses 23 symptoms (Echemendia et al., 2017). Within the RTL care plan, the 23 symptoms were categorized into four major domains: sleep, physical, cognitive, and emotion, based on the REAP concussion symptom wheel (McAvoy, 2019). Students could endorse a symptom not included in the symptom checklist, designed as "other". The checklist asked students to identify symptom severity over the last two days on a scale from $0-6(0=$ no symptoms, $1-2=$ mild symptoms, $3-4=$ moderate symptoms, and 5-6 = severe symptoms).

The temporary adjustment recommendations portion of the RTL care plan was created using a review of concussion literature and existing concussion evaluation tools, as well as input from both school staff and researcher clinicians with expertise in adolescent concussion. The care plan was also designed to complement the symptom checklist and facilitates recommendations and implementation of academic accommodations. There are twentyone possible accommodations across the same four general categories of the symptom checklist (sleep, cognitive, physical, and emotional). Accommodation categories were mapped to symptom categories by expert clinicians on the study team who provide concussion care and who reviewed the literature. Some accommodations fit in more than one of the general categories because they are effective for more than one symptom category.

During each weekly visit with the RTL champion, students were evaluated for symptoms and offered tailored symptom-based academic accommodations. Symptoms and accommodations were re-reevaluated each week. RTL champions were also able to recommend other accommodations not within an accommodation domain. The RTL champion communicated accommodations to teachers and other relevant school staff for implementation.

\subsection{Data analysis}

Descriptive statistics were used to characterize concussion symptoms and corresponding accommodations. If a symptom or accommodation was not indicated on the RTL consult form, then it was coded as not experienced. This was done based on the study team's understanding of how the RTL care plan was used after consultation with RTL coordinators; many RTL coordinators did not indicate severity values for symptoms a student did not experience. For some analyses, concussion symptoms were dichotomized as either absent or present where a symptom was considered present if the reported severity was one or greater.

Concussion symptoms were examined as: 1) average number of symptoms experienced per student for each of the four weeks, 2) average total severity of symptoms per student for each of the four weeks, where total symptom severity was calculated as the sum of severity scores for all symptoms reported on the symptom checklist, 3) ranking of the top 10 most frequently experienced symptoms during week one based on average severity, and 4) difference in average number of symptoms experienced and total symptom severity at first visit between students who no longer required the RTL care plan after 1-2 weeks (short duration) and students who remained in the program for 3-4 weeks (long duration). Two-sided independent $t$-tests were used to compare the number of unique symptoms, total severity score, and average severity per symptom of the short duration group and the long duration group at week one.

Temporary accommodations were examined in three ways. 1) The total number of weekly accommodations offered to students over the full study period was calculated. Since accommodations are assessed weekly, accommodations were counted for each week they were provided. 2) The five most administered temporary accommodations were identified and ranked by frequency. 3) Accommodations were compared to reported symptoms in each individual weekly care plan to assess whether students who reported a concussion symptom in each domain also received a corresponding accommodation in that domain (sleep, cognitive, physical, or emotional). If a student experienced one or more symptoms in each domain and received one or more accommodations in the same domain, they were classified as having received a corresponding accommodation. If students experienced one or more symptoms in each domain but were not offered an accommodation in that domain, they were classified as not having been offered a corresponding accommodation.

Statistical analyses were conducted in RStudio using R version 4.0.0 (R Studio Team, 2020). This study was approved by the University of Washington Institutional Review Board.

\section{Results}

Table 1 details characteristics of the 115 high school students who were diagnosed with concussion 
and received the RTL care plan during a total of 155 weekly check-ins at five large public high schools. Most (54\%) students reported at least one pre-existing condition; the two most common were prior concussions (24\%) and depression (16\%). Forty-five percent $(N=52)$ were symptom-free after two weeks and stopped receiving the RTL care plan, whereas 55\% $(N=63)$ required the RTL care plan for three $(34 \%)$ or four $(21 \%)$ weeks.

The average number of unique symptoms, average total symptom severity score, and average severity per symptom per student decreased from weeks one through four of the RTL care plan (Table 2). Figure 1 shows the most frequently reported symptoms during week one: headache (88\%), feeling slowed down (84\%), feeling sleepy (83\%), and difficulty concentrating (79\%). During week one, headache had the highest mean severity (mean 3.13, SD 1.66) followed by feeling sleepy (mean 2.63, SD 1.65), and feeling

Table 1

Demographics and Characteristics of Study Participants

\begin{tabular}{lc}
\hline Participant Characteristics & $\begin{array}{c}\text { Students } \\
(N=115) \\
N(\%)\end{array}$ \\
\hline RTL Care Plan Consults & \\
One & $5(4)$ \\
Two & $47(41)$ \\
Three & $39(34)$ \\
Four & $24(21)$ \\
School & \\
A & $32(28)$ \\
B & $23(20)$ \\
C & $44(38)$ \\
D & $12(10)$ \\
E & $4(3)$ \\
Pre-Existing Condition(s) & \\
None & $53(46)$ \\
Multiple Concussions & $28(24)$ \\
Depression & $18(16)$ \\
Attention Deficits & $12(10)$ \\
History of Migraines & $9(8)$ \\
Recent Concussion & $8(7)$ \\
Other Head Injury & $7(6)$ \\
Learning Disability & $6(5)$ \\
Sleep Disorder & $0(0)$ \\
\hline &
\end{tabular}

slowed down (mean 2.56, SD 1.63). Four of the 10 most common symptoms during week one are classified within the physical symptom domain, four are classified within the cognitive domain, and two are within the sleep domain. No symptoms from the emotional domain were within the top 10 most common symptoms during week one.

Table 3 examines differences in number and severity of symptoms by duration of RTL care plan use. Compared to students in the short duration group, students in the long duration RTL care plan group reported more unique symptoms (mean 13.6, standard deviation [SD] 4.3 vs. mean 11.6, SD 5.8; p 0.038 ), higher total severity score (mean 40.5, SD 19.9 vs. mean 29.7, SD 20.8; p 0.005), and higher average severity per symptom (mean 2.9 , SD 0.9 vs. mean 2.4, SD 0.8; p 0.007) at week one.

Accommodations were reassessed each week. In total, 1,127 weekly accommodations were offered to students over the course of the study period; the most common were extra time and assistance on assignments $(17 \%)$ and removal from physical education (14\%; Table 4). The top five most common accommodations accounted for $60 \%$ of all accommodations offered. Supplementary Table 1 outlines the number of times each possible accommodations was recommended by the RTL coordinator. An average of 9.8 accommodations per student were made during the duration of their RTL care plan use, and an average of 3.6 accommodations were made per visit. The average number of accommodations made per student decreased each week from 6.3 accommodations per student at the first visit, to 2.5 at the second, 1.6 at the third, and 1.3 at the fourth.

While least commonly reported, symptoms in the emotional symptom domain received corresponding accommodations most often (127/155 reports: $82 \%$ of occurrences). Physical and cognitive symptoms received corresponding accommodations $79 \%$ and $70 \%$ of the time, respectively. Sleep symptoms received corresponding accommodations the least often (145/219 reports: $66 \%)$.

Table 2

Number of Symptoms and Total Severity by Week

\begin{tabular}{lcccc}
\hline Number of Symptoms & Week 1 & Week 2 & Week 3 & Week 4 \\
and Total Severity by & $N=115$ & $N=110$ & $N=63$ & $N=24$ \\
Week & Mean $(S D)$ & Mean $(S D)$ & Mean $(S D)$ & Mean $(S D)$ \\
\hline Number of Symptoms & $12.68(5.1)$ & $7.75(6.6)$ & $5.19(5.7)$ & $4.17(4.6)$ \\
Total Symptom Severity & $35.60(20.9)$ & $17.51(18.3)$ & $10.19(14.5)$ & $8.42(11.6)$ \\
Average Symptom Severity & $2.65(0.9)$ & $2.03(0.7)$ & $1.66(0.8)$ & $1.74(0.9)$ \\
\hline
\end{tabular}

$S D=$ standard deviation. 

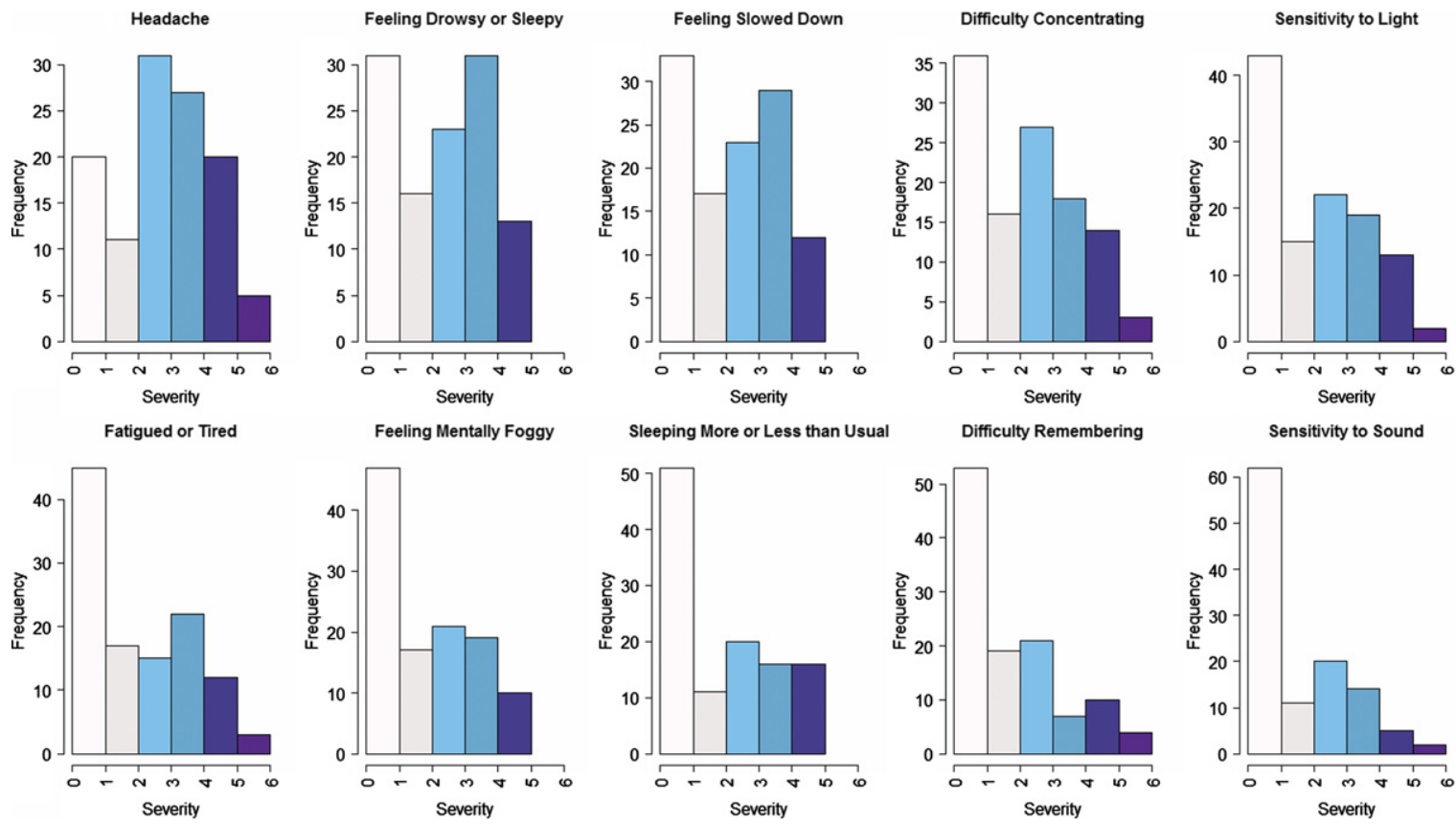

Fig. 1 . The top 10 most frequently reported symptoms in week 1 by mean severity. Symptoms are rated by participants on a $0-6$ scale $(0=$ no symptoms, $1-2=$ mild symptoms, 3-4=moderate symptoms, and 5-6= severe symptoms). Mean severity decreases as you move to the right and down.

Table 3

A Comparison of the Number of Symptoms and Total Severity of Symptoms Reported in Week 1 by Students in the Short Duration Group (1 or 2 Weeks) vs. the Long Duration Group (3 or 4 Weeks)

\begin{tabular}{lccc}
\hline Week 1 Symptom & Short Group & Long Group & \\
Comparison Between & $N=52$ & $N=63$ & $P$ value \\
Long and Short Group & Mean $(S D)$ & Mean $(S D)$ & \\
\hline Number of Symptoms & $11.60(5.8)$ & $13.57(4.3)$ & 0.038 \\
Total Symptom Severity & $29.67(20.8)$ & $40.49(19.9)$ & 0.005 \\
Average Symptom Severity & $2.40(0.8)$ & $2.85(0.9)$ & 0.007 \\
\hline
\end{tabular}

$S D=$ standard deviation.

\section{Discussion}

This study aimed to better understand concussion symptoms and need for temporary accommodations. Using a four week school-based student centered RTL care plan (Conrick et al., 2020), we found that: 1) many students who reported a concussion to school had a history of prior concussion and depression, 2) most students experienced concussion symptoms beyond two weeks, 3) students in the long symptom duration group had more symptoms and more severe symptoms during the first week of reporting compared to students whose symptoms resolved within 1-2 weeks from RTL care plan start, 4) RTL coordinators recommended corresponding
Table 4

Top Five Most Common Accommodations Recommended Across All 4 Visits

\begin{tabular}{lc}
\hline & $\begin{array}{c}\text { Number of Weekly } \\
\text { Accommodations } \\
N=1,127 \\
N(\%)\end{array}$ \\
& $187(17)$ \\
\hline Extra time and assistance on assignments & $154(14)$ \\
Removal from Physical Education (PE) & \\
$\quad$ Courses & $127(12)$ \\
No or reduced screen time & $110(10)$ \\
Rest breaks: scheduled or as needed in a & \\
$\quad$ quite area & $99(9)$ \\
\hline No testing &
\end{tabular}

temporary accommodations for reported symptoms across all domains in the majority of cases, and 5) RTL coordinators least often recommended corresponding accommodations for sleep symptoms. In combination, these data collected and provided by school staff suggest that students who reported concussion symptoms to schools needed and received many student-centered temporary accommodations. This is the first study to report on symptom based temporary accommodations provided by urban public high schools to support students with concussion who RTL. 
We compared first week symptoms experienced by students in the short duration group ( $\leq 2$ weeks on the RTL care plan) to those experienced by students in the long duration group ( $>2$ weeks on the RTL care plan) to explore if students who required the RTL care plan, and thus school support, beyond two weeks could be identified earlier after reporting. This exploration allowed us to better understand the need for identification of students at risk of prolonged concussion symptoms, could facilitate development of mitigation strategies that reduce number and severity of early symptoms, and may prepare schools to provide the spectrum of needed and appropriate accommodations based on possible recovery trajectories. While the Centers for Disease and Prevention currently provides general guidance on what schools can do to address concussion symptoms, there is no mapping of symptoms to accommodations like there is in the student-centered RTL care plan we developed, implemented and report on (Centers for Disease Control and Prevention, n.d.). Future research should examine if a school-based symptom checklist such as that used in the RTL care plan could be used as a prognostication aid or screening tool for students at risk of prolonged symptoms after concussion.

To increase our understanding of how schools accommodate students experiencing concussion symptoms, we evaluated the categories of symptoms which most often received corresponding accommodations. We found that students receiving the RTL care plan were very likely to be offered an accommodation that correctly mapped to symptoms across all four symptom categories. Symptoms categorized as emotional symptoms received corresponding accommodations most often, perhaps due to their feasibility or perceived importance. In contrast, symptoms categorized as sleep symptoms received a corresponding accommodation the least frequently, perhaps because many sleep accommodations, such as offering a later start or an early departure, also require participation and coordination of parental schedules. Overall, the high rates of corresponding accommodations recommended by RTL coordinators in public high schools in this study suggests that implementation of an RTL care plan provides a mechanism for schools to align themselves with Centers for Disease Control and Prevention guidance and results in tailored symptom based and student-centered accommodations (Centers for Disease Control and Prevention, n.d.). Next steps may involve further investigation of optimizing delivery of temporary accommodations, including the administration of specific accommodations for cognitive problems, eye tracking, reading, and autonomic problems that likely make up the majority of concussion symptoms that may interfere with school re-entry (Master et al., 2016). Future work should also evaluate whether early provision of temporary accommodations is associated with improved academic outcomes and symptom resolution after concussion.

While we did not formally examine school workflow or cost of RTL use, it is notable that students were given almost four accommodations per week and nearly 10 accommodations over their duration on the RTL care plan. Moreover, the total number of accommodations provided across the five schools was large, which could increase school costs and affect workflow. For example, greater demand for assistance on assignments could require additional time from teachers or classroom aids, which may or may not be available, especially in resource constrained settings. School policy decisions on use of an RTL care plan should be based on research that weighs the cost of RTL care plan implementation and temporary accommodations provided against potential benefits such as concussion symptom recovery and student achievement (Hux et al., 2010; Russell et al., 2016, 2017; Wasserman et al., 2016).

This study has some limitations. Week one on the RTL care plan represents the first time students reported concussion symptoms in school, interreacted with the RTL champion and received the RTL care plan; this timeframe may not correspond to the first week after concussion. Our observation that over $45 \%$ of students have resolution of symptoms within two RTL visits may not reflect symptom resolution within two weeks after injury and thus underestimate concussion symptom duration. This was a convenience sample and not a populationbased study, there was no control group, and we did not enroll all students in the five public high schools. These gaps prevent causal inference about use of the RTL care plan and associated concussion symptom duration. Students in this study reported a history of prior concussions which may represent more severe cases that might overestimate the need for temporary accommodations. While we had assurances that temporary accommodations recommended by the RTL champion and provided by school staff were implemented with high fidelity, we did not directly observe this relationship (Wan \& Nasr, 2020). Additionally, seemingly good accommodation correspondence could be an artifact of RTL champions being over-inclusive when recommending accommo- 
dations, and RTL champion and student level effects cannot be teased apart. Since we only had data from five public high schools, school concerns of identification precluded presentation of school or student characteristics, and there may be socioeconomic or demographic differences that affect the generalizability of this work. We also had no data on pre-existing anxiety disorders which are known to increase symptom burden and recovery time (Martin et al., 2020). Finally, since we had limited access to student demographic data, we were unable to identify patterns of symptom recovery by injury mechanism, gender, grade, English proficiency, or race.

\section{Conclusions}

Students who reported concussion symptoms to schools received many student-centered temporary accommodations. Use of an RTL care plan may identify students who will require longer term support and support RTL of students with concussion. This study helped us better understand concussion symptoms that are reported to schools as well as corresponding needs for temporary accommodations among public high school students. These findings provide new information to inform discussion regarding the need for school-based screening for concussion symptoms and temporary accommodations. The fact that public high schools were able to successfully provide symptom-based accommodations speaks to the presence of some existing infrastructure to care for students with concussion and suggests that expansion of RTL programs may be viable.

\section{Acknowledgments}

This work was supported by the Harborview Injury Prevention and Research Center and the Department of Anesthesiology and Pain Medicine, University of Washington, Seattle, WA, USA.

\section{Conflict of interest}

The authors have no conflicts of interest to declare.

\section{Supplementary material}

The supplementary material is available in the electronic version of this article: https://dx.doi.org/ 10.3233/NRE-210182.

\section{References}

Brown, N. J., Mannix, R. C., O’Brien, M. J., Gostine, D., Collins, M. W., \& Meehan, W. P. (2014). Effect of cognitive activity level on duration of post-concussion symptoms. Pediatrics, 133(2). https://doi.org/10.1542/peds.2013-2125

Bryan, M. A., Rowhani-Rahbar, A., Comstock, R. D., \& Rivara, F. (2016). Sports-and recreation-related concussions in US youth. Pediatrics, 138(1). https://doi.org/10.1542/peds.2015-4635

Carson, J. D., Lawrence, D. W., Kraft, S. A., Garel, A., Snow, C. L., Chatterjee, A., Libfeld, P., MacKenzie, H. M., Thornton, J. S., Moineddin, R., \& Frémont, P. (2014). Premature return to play and return to learn after a sport-related concussion: physician's chart review. Canadian Family Physician Medecin de Famille Canadien, 60(6), e310, e312-5.

Castile, L., Collins, C. L., McIlvain, N. M., \& Comstock, R. D. (2012). The epidemiology of new versus recurrent sports concussions among high school athletes, 2005-2010. British Journal of Sports Medicine, 46(8), 603 LP - 610. https:// doi.org/10.1136/bjsports-2011-090115

Centers for Disease Control and Prevention. (n.d.). Returning to School After a Concussion: A Fact Sheet for School Professionals. https://www.cdc.gov/headsup/pdfs/schools/tbi_ returning_to_school-a.pdf

Chrisman, S. P. D., Lowry, S., Herring, S. A., Kroshus, E., Hoopes, T. R., Higgins, S. K., \& Rivara, F. P. (2019). Concussion Incidence, Duration, and Return to School and Sport in 5- to 14-Year-Old American Football Athletes. The Journal of Pediatrics, 207, 176-184.e1. https://doi.org/10.1016/ j.jpeds.2018.11.003

Conrick, K. M. G., Moore, M., Abbotts, L., Widdice, L., Hoag, S., Kroshus, E., Philipson, E. B., Jinguji, T., Weiner, B. J., Glang, A., Rivara, F. P., Chrisman, S. P. D., Dickason, C. Q., \& Vavilala, M. S. (2020). Community-Engaged Approach to the Development and Implementation of a Student-Centered Return to Learn Care Plan After Concussion. Journal of School Health, 90(11). https://doi.org/10.1111/josh.12948

Corwin, D. J., Zonfrillo, M. R., Master, C. L., Arbogast, K. B., Grady, M. F., Robinson, R. L., Goodman, A. M., \& Wiebe, D. J. (2014). Characteristics of prolonged concussion recovery in a pediatric subspecialty referral population. Journal of Pediatrics, 165(6). https://doi.org/10.1016/j.jpeds.2014.08.034

Echemendia, R. J., Meeuwisse, W., McCrory, P., Davis, G. A., Putukian, M., Leddy, J., Makdissi, M., Sullivan, S. J., Broglio, S. P., Raftery, M., Schneider, K., Kissick, J., McCrea, M., Dvořák, J., Sills, A. K., Aubry, M., Engebretsen, L., Loosemore, M., Fuller, G., ... Herring, S. (2017). The Sport Concussion Assessment Tool 5th Edition (SCAT5): Background and rationale. British Journal of Sports Medicine, 51(11). https://doi.org/10.1136/bjsports-2017-097506

Gessel, L. M., Fields, S. K., Collins, C. L., Dick, R. W., \& Comstock, R. D. (2007). Concussions among United States high school and collegiate athletes. Journal of Athletic Training, 42(4), 495-503.

Grady, M. F., \& Master, C. L. (2017). Return to school and learning after concussion: Tips for pediatricians. In Pediatric Annals (Vol. 46, Issue 3). https://doi.org/10.3928/1938235920170220-04

Harris, P. A., Taylor, R., Thielke, R., Payne, J., Gonzalez, N., \& Conde, J. G. (2009). Research electronic data capture (RED Cap)-A metadata-driven methodology and workflow process for providing translational research informatics support. 
Journal of Biomedical Informatics, 42(2). https://doi.org/ 10.1016/j.jbi.2008.08.010

Hux, K., Bush, E., Zickefoose, S., Holmberg, M., Henderson, A., \& Simanek, G. (2010). Exploring the study skills and accommodations used by college student survivors of traumatic brain injury. Brain Injury, 24(1), 13-26. https://doi.org/10.3109/ 02699050903446823

Marar, M., McIlvain, N. M., Fields, S. K., \& Comstock, R. D. (2012). Epidemiology of concussions among United States high school athletes in 20 sports. The American Journal of Sports Medicine, 40(4), 747-755. https://doi.org/10.1177/ 0363546511435626

Marshall, S. W., Guskiewicz, K. M., Shankar, V., McCrea, M., \& Cantu, R. C. (2015). Epidemiology of sports-related concussion in seven US high school and collegiate sports. Injury Epidemiology, 2(1), 13. https://doi.org/10.1186/s40621-0150045-4

Martin, A. K., Petersen, A. J., Sesma, H. W., Koolmo, M. B., Ingram, K. M., Slifko, K. B., Nguyen, V. N., Doss, R. C., \& Linabery, A. M. (2020). Concussion symptomology and recovery in children and adolescents with pre-existing anxiety. Journal of Neurology, Neurosurgery, and Psychiatry, 91(10), 1060-1066. https://doi.org/10.1136/jnnp-2020-323137

Master, C. L., Scheiman, M., Gallaway, M., Goodman, A., Robinson, R. L., Master, S. R., \& Grady, M. F. (2016). Vision Diagnoses Are Common After Concussion in Adolescents. Clinical Pediatrics, 55(3), 260-267. https://doi.org/10.1177/ 0009922815594367

McAvoy, K. (2019). REAP The Benefits of Good Concussion Management.

McCrory, P., Meeuwisse, W., Dvořák, J., Aubry, M., Bailes, J., Broglio, S., Cantu, R. C., Cassidy, D., Echemendia, R. J., Castellani, R. J., Davis, G. A., Ellenbogen, R., Emery, C., Engebretsen, L., Feddermann-Demont, N., Giza, C. C., Guskiewicz, K. M., Herring, S., Iverson, G. L., .. Vos, P. E. (2017). Consensus statement on concussion in sport-the 5 th international conference on concussion in sport held in Berlin, October 2016. British Journal of Sports Medicine, 51(11), 838-847. https:// doi.org/10.1136/bjsports-2017-097699

Meehan, W. P. 3rd, d'Hemecourt, P., \& Comstock, R. D. (2010). High school concussions in the 2008-2009 academic year: mechanism, symptoms, and management. The American Journal of Sports Medicine, 38(12), 2405-2409. https://doi.org/ $10.1177 / 0363546510376737$

O’Connor, K. L., Baker, M. M., Dalton, S. L., Dompier, T. P., Broglio, S. P., \& Kerr, Z. Y. (2017). Epidemiology of Sport-Related Concussions in High School Athletes: National Athletic Treatment, Injury and Outcomes Network (NATION), 2011-2012 Through 2013-2014. Journal of Athletic Training, 52(3), 175-185. https://doi.org/10.4085/1062-6050-52.1.15

Purcell, L. K., Davis, G. A., \& Gioia, G. A. (2019). What factors must be considered in "return to school" following concussion and what strategies or accommodations should be followed? A systematic review. British Journal of Sports Medicine, 53(4). https://doi.org/10.1136/bjsports-2017-097853
R Studio Team. (2020). R Studio. In R.S. ed. http://www.rstudio. com/

Ransom, D. M., Vaughan, C. G., Pratson, L., Sady, M. D., McGill, C. A., \& Gioia, G. A. (2015). Academic effects of concussion in children and adolescents. Pediatrics, 135(6). https://doi.org/ 10.1542/peds.2014-3434

Rosenthal, J. A., Foraker, R. E., Collins, C. L., \& Comstock, R D. (2014). National High School Athlete Concussion Rates From 2005-2006 to 2011-2012. The American Journal of Sports Medicine, 42(7), 1710-1715. https://doi.org/10.1177/ 0363546514530091

Russell, K., Hutchison, M. G., Selci, E., Leiter, J., Chateau, D., \& Ellis, M. J. (2016). Academic Outcomes in High-School Students after a Concussion: A Retrospective PopulationBased Analysis. PloS One, 11(10), e0165116. https://doi.org/ 10.1371/journal.pone.0165116

Russell, K., Selci, E., Chu, S., Rozbacher, A., \& Ellis, M. (2017). Academic outcomes and accommodations following adolescent sport-related concussion: a pilot study. Concussion (London, England), 2(4), CNC51.https://doi.org/10.2217/ cnc-2017-0009

Sady, M. D., Vaughan, C. G., \& Gioia, G. A. (2011). School and the Concussed Youth: Recommendations for Concussion Education and Management. In Physical Medicine and Rehabilitation Clinics of North America (Vol. 22, Issue 4). https:// doi.org/10.1016/j.pmr.2011.08.008

Silverberg, N. D., \& Iverson, G. L. (2013). Is rest after concussion "the best medicine?": Recommendations for activity resumption following concussion in athletes, civilians, and military service members. Journal of Head Trauma Rehabilitation, 28(4). https://doi.org/10.1097/HTR.0b013e31825ad658

Wan, A. N., \& Nasr, A. S. (2020). Return to learn: An ethnographic study of adolescent young adults returning to school post-concussion. Journal of Clinical Nursing. https://doi.org/ 10.1111/jocn. 15617

Wasserman, E. B., Bazarian, J. J., Mapstone, M., Block, R., \& van Wijngaarden, E. (2016). Academic Dysfunction After a Concussion Among US High School and College Students. American Journal of Public Health, 106(7), 1247-1253. https:// doi.org/10.2105/AJPH.2016.303154

West, T. A., \& Marion, D. W. (2014). Current recommendations for the diagnosis and treatment of concussion in sport: a comparison of three new guidelines. Journal of Neurotrauma, 31(2), 159-168. https://doi.org/10.1089/neu.2013.3031

Zemek, R., Barrowman, N., Freedman, S. B., Gravel, J., Gagnon, I., McGahern, C., Aglipay, M., Sangha, G., Boutis, K., Beer, D., Craig, W., Burns, E., Farion, K. J., Mikrogianakis, A., Barlow, K., Dubrovsky, A. S., Meeuwisse, W., Gioia, G., Meehan, W. P., ... Moore, J. (2016). Clinical risk score for persistent postconcussion symptomsamong children with acute concussion in the ED. JAMA - Journal of the American Medical Association, 315(10). https://doi.org/10.1001/jama.2016.1203 